\title{
Short and medium-term effects of secundum atrial septal defect percutaneous closure using the Amplatzer Septal Occluder in the elderly
}

\author{
Andrew Broadley ${ }^{*}$, Laisha Gogola ${ }^{2}$, Carl Roobottom ${ }^{3}$, Nicholas Ring ${ }^{3}$ and Andrew J Marshall ${ }^{2}$ \\ ${ }^{1}$ Consultant Cardiologist, Yeovil District Hospital, Yeovil BA21 4AT, UK \\ ${ }^{2}$ Department of Cardiology, Level 6, Derriford Hospital, Plymouth PL6 8DH, UK \\ ${ }^{3}$ Department of Radiology, Level 6, Derriford Hospital, Plymouth PL6 8DH, UK
}

\begin{abstract}
Aim: to assess the effects of percutaneous secundum atrial septal defect (ASD) closure in the elderly.

Methods and results: Descriptive, retrospective study in a large Regional University Teaching Hospital. Subjects were 11 patients aged over 60 (mean age 72 [range 62 to 83], 3 male) at the time they underwent percutaneous closure of a secundum ASD using an Amplatzer septal occluder (ASO). Post-closure the following parameters were significantly reduced: heart size on serial chest X-ray, from a mean (standard deviation) of $16.7(2.1) \mathrm{cm}$ to $14.8(1.3) \mathrm{cm}(\mathrm{p}=0.016)$ after $4.5(2.1)$ months; pulmonary vascularity on serial chest X-ray; right ventricular diastolic diameter on serial transthoracic echocardiogram, from $4.2(0.8) \mathrm{cm}$ to $3.0(0.74) \mathrm{cm}$ $(\mathrm{p}<0.001)$ after a mean of 15 (12.2) months; and right ventricular systolic pressure measured indirectly $(\mathrm{n}=4)$. Symptoms, particularly shortness of breath, also seemed to improve although they were not quantitatively assessed.

Conclusion: percutaneous closure of ASD in the elderly using an ASO results in significant reduction in right ventricle and pulmonary artery size, improved haemodynamics and probably also symptoms. On this basis it should be considered in all cases where it is technically feasible, in preference to continuing medical therapy.
\end{abstract}

\section{Introduction}

Atrial septal defect (ASD) is compatible with survival to the age of 80 and beyond, depending on the size of the defect and the presence of co-morbidities. Bigger defects causing more prominent symptoms and signs are more likely to be diagnosed in childhood and early adult life but there is also a small and steady stream of elderly adults in whom the diagnosis is made for the first time. Treatment options include medical management, percutaneous closure and open surgical closure. There is clear evidence that children and young adults with an ASD and consequent symptoms, or who are asymptomatic but are shown to have a haemodynamically significant shunt, do better symptomatically, haemodynamically and in terms of survival if the ASD is closed [1-3].

Evidence that surgical closure of an ASD improves symptoms and survival in more elderly patients also exists [4] yet despite this debate continued until at least the late 1990s about whether ASD should be closed in elderly patients with minimal or no symptoms $[5,6]$. In part this was due to the greater risk of death complicating surgical closure in elderly patients, and to a lack of evidence that closure offered significant benefits over medical treatment. However, now that percutaneous closure of ASD is widely available, and based on the reasonable - though not formally tested - assumption that mortality following percutaneous closure in the elderly will be about as low as it is in children and young adults, resistance to advocating the procedure in the elderly should diminish if the procedure can be shown to offer significant symptomatic and haemodynamic advantages over medical treatment. It may also offer survival advantages but this premise will be hard to test because if there are symptomatic and haemodynamic advantages to closure a randomised trial of closure versus medical treatment will be difficult to justify.

\section{Methods}

All patients from our institution who have undergone percutaneous ASD closure were identified and the data on those who underwent the procedure after the age of 60 were reviewed. From their notes were abstracted, as far as was possible, pertinent clinical details as follows: age at diagnosis; symptoms at diagnosis and their duration; co-morbidities; weight and diuretic dose. Their pre-operative transthoracic (TTE) and transoesophageal (TOE) echocardiogram tapes, their post-operative TTE, and their cardiac catheterisation studies were all reviewed and from these were obtained selected measurements namely RV diastolic diameter (measured in the parasternal long axis view according to the recommendations of the American Society of Echocardiography [7]), ASD size (measured by balloon sizing at the time of closure), left-to right shunt ratio and indirect (from TTE) and direct (from catheterisation)

Correspondence to: Andrew Broadley, Consultant Cardiologist, Yeovil District Hospital, Yeovil BA21 4AT, UK Tel: +01935 383006, E-mail: andrew.broadley@ ydh.nhs.uk

Key words: atrial septal defect, Amplatzer septal occluder; elderly

Received: September 28, 2017; Accepted: October 25, 2017; Published: October 28,2017 
pulmonary artery pressures. Lastly, their pre- and post-operative chest $\mathrm{X}$-rays (CXR) were obtained and the cardiac silhouette diameter was measured on each. All CXR were departmental PA films. The CXR films were then placed in random order on a viewing station with a patch over the centre of the cardiac silhouette to obscure the closure device (if present) and two radiologists were asked to separately grade the size of the central and peripheral pulmonary arteries. Both central and peripheral pulmonary arteries were graded on a simple, semi-quantitative three-point scale as follows: $1=$ normal; $2=$ mild or moderate enlargement; 3 = severe enlargement.

Pre- and post-procedure values were compared. Student's paired t-test was used for normally distributed, continuous variables and the Wilcoxon rank-sum test for categories. A p value of $<0.05$ was considered significant.

\section{Results}

\section{Subjects}

Eleven patients were identified (mean age 72 [range 62 to 83], 3 male, mean follow up 16 months [range 5 to 32]) who had percutaneous ASD closure aged 60 or over, all of whom received an Amplatzer Septal Occluder (ASO). Left to right shunt ratio was calculated in 8 patients at cardiac catheterisation, prior to closure (mean 2.4 [range 1.4 to 3.2 ]).

\section{Clinical details}

These are summarised in Table 1. Nine patients were symptomatic and two were diagnosed after TTE performed because a murmur had been heard. Among the symptomatic patients the mean duration of symptoms was at least 56 months, which is an underestimate as 3 patients could be no more specific than to say they had been breathless for at least 10 years.

Patients' clinical records did not, as a rule, specifically grade their breathlessness according to New York Heart Association (NYHA) heart failure criteria and so these were estimated from the information that

Table 1. Clinical details

\begin{tabular}{|c|c|c|c|c|c|c|}
\hline Sex & Age & Symptoms & $\begin{array}{l}\text { Duration } \\
\text { (months) }\end{array}$ & Co-morbidity & Rhythm & Diuretic \\
\hline $\mathrm{F}$ & 70 & $\begin{array}{l}\text { SOB, } \\
\text { murmur }\end{array}$ & $>120$ & $\begin{array}{l}\text { HT,? Alcoholic } \\
\text { cardiomyopathy }\end{array}$ & SR & $\mathrm{F} 40$ \\
\hline $\mathrm{F}$ & 72 & SOB & $>120$ & Nil & SR & F40 \\
\hline M & 74 & $\begin{array}{l}\text { SOB, } \\
\text { fatigue }\end{array}$ & 24 & HT & SR & No \\
\hline $\mathrm{F}$ & 83 & $\begin{array}{l}\text { SOB, } \\
\text { oedema }\end{array}$ & 6 & PAF & SR & $\mathrm{F} 80, \mathrm{~A} 5$ \\
\hline $\mathrm{F}$ & 72 & $\begin{array}{l}\text { SOB, } \\
\text { oedema }\end{array}$ & 3 & $\mathrm{HT}, \mathrm{AF}$ & $\mathrm{AF}$ & B2.5 \\
\hline $\mathrm{F}$ & 73 & SOB & 69 & HT & SR & F40 \\
\hline M & 62 & SOB & 13 & AF, HT & $\mathrm{AF}$ & No \\
\hline M & 78 & $\begin{array}{l}\text { "CCF" on } \\
\text { pre-op echo }\end{array}$ & $>120$ & $\begin{array}{l}\text { PAF, COPD Ca } \\
\text { colon }\end{array}$ & SR & F40 \\
\hline $\mathrm{F}$ & 65 & $\begin{array}{l}\text { Health } \\
\text { check, } \\
\text { murmur }\end{array}$ & NA & Nil & SR & No \\
\hline $\mathrm{F}$ & 68 & $\begin{array}{l}\text { Tiredness, } \\
\text { murmur }\end{array}$ & NA & HT & SR & B2.5 \\
\hline $\mathrm{F}$ & 72 & $\begin{array}{l}\text { SOB } \\
\text { palpitations } \\
\text { oedema }\end{array}$ & 30 & Nil (? PAF) & SR & F80, A5 \\
\hline \multicolumn{7}{|c|}{$\begin{array}{l}\text { Abbreviations: } ?=\text { possible, } \mathrm{A}=\text { amiloride }(\text { dose in } \mathrm{mg}), \mathrm{AF}=\text { atrial fibrillation, } \mathrm{B} \\
=\text { bendroflumethazide }(\text { dose in } \mathrm{mg}), \mathrm{Ca}=\text { carcinoma, } \mathrm{COPD}=\text { chronic obstructive } \\
\text { pulmonary disease, } \mathrm{F}=\text { furosemide }(\text { dose in } \mathrm{mg}), \mathrm{HT}=\text { hypertension, } \mathrm{PAF}=\text { paroxysmal } \\
\mathrm{AF}, \mathrm{SOB}=\text { shortness of breath, } \mathrm{SR}=\text { sinus rhythm. }\end{array}$} \\
\hline
\end{tabular}

was recorded. NYHA class 2, which is very wide, was subdivided into $2 \mathrm{a}$ and $2 \mathrm{~b}$, representing the less and more severe halves of the range respectively. The median estimated score fell from $2 b$ (range $2 a$ to 3 ) to $2 \mathrm{a}$ (range 1 to $2 \mathrm{~b}$ ) (Figure 1 and Table 2). These figures certainly suggest an improvement in breathlessness across the board, which is borne out by such comments in patients' records as, "feels much improved", and "less SOB", but it would be inappropriate to apply statistics to such qualitative and potentially biased assessments.

\section{Echo data}

RV diastolic diameter decreased significantly (Table 2). Tricuspid regurgitation (TR) was detected and recorded in all patients preoperatively but in only 4 post-operatively, consistent with reduced RV volume and reduced "functional" TR secondary to stretching of the tricuspid valve annulus. Indirectly estimated pulmonary artery pressure (minus right atrial pressure) fell significantly in these 4 patients (Table 2, see also Limitations section of Discussion).

\section{CXR data}

The cardiac silhouette diameter and central and peripheral pulmonary artery sizes fell significantly (Table 2, Figure 2). Interestingly, when we examined the latest available CXR for the 8 patients who had subsequently had further films taken as part of their follow up, cardiac silhouette diameter remained stable, suggesting early cardiac structural improvements are maintained in the medium term.

\section{Discussion}

The principal findings of this study are that overall heart size (measured as RV diastolic diameter on TTE, and cardiac silhouette diameter on CXR) and pulmonary artery size fell significantly in the short and medium term after percutaneous closure of ASD in a group of patients aged over 60 .

Previously it has been established that surgical closure of an ASD in children or adults with symptoms is of symptomatic, haemodynamic and prognostic benefit $[1,2]$. The upper age limit at which these benefits have been shown was extended by Attie et al who randomised over 500 patients aged over 40 (mean age 51 but including over 100 patients aged " $>60$ ") to medical treatment or surgical closure [3]. Percutaneous closure in children and young adults offers advantages over surgical closure in that procedural morbidity is reduced. However, there remains controversy over whether ASD should be closed in the elderly i.e. in those over 60 and especially those in their 70s and 80s [6]. The main reasons for this are: 1) there is some evidence that prognosis is no better with surgical closure than with medical therapy, and this may apply particularly in the elderly who are by default a self-selected group whose ASD has not brought them to medical attention earlier [5]; 2) there is a perception that complications of surgical closure are more likely to occur in those with heart failure or raised pulmonary pressures [8], and both these clinical features are common in elderly, symptomatic patients; and 3) it has been suggested that right heart remodelling is less likely to occur following closure in older patients [9].

There are no prospective, randomised, controlled trials of ASD closure versus medical therapy in the elderly. Recently, Swan et al retrospectively reviewed the short term haemodynamic effects of percutaneous ASD closure in 50 patients aged over 60 [10]. They showed that RV diastolic diameter and pressure were both reduced significantly after approximately 6 weeks. Yalonetsky and Lorber have also reported their experience with ASD closure in the elderly [11]. They retrospectively examined the records of 23 patients aged over 60 
Table 2. Clinical, echocardiographic and radiographic effects of ASD closure

\begin{tabular}{|c|c|c|c|}
\hline Clinical & pre & post & $\mathbf{p}$ \\
\hline estimated NYHA class (mean [range]) & $2 \mathrm{~b}[2 \mathrm{a}$ to 3$]$ & $2 \mathrm{a}[1$ to $2 \mathrm{~b}]$ & NA \\
\hline oedema (n) & 3 & 0 & NA \\
\hline weight (kg) & $66(13)$ & $69(11)$ & NS \\
\hline \multicolumn{4}{|l|}{ Echocardiographic } \\
\hline right ventricle $(\mathrm{RV})$ diastolic diameter $(\mathrm{cm})$ & $4.2(0.8)$ & $3.0(0.7)$ & $<0.001$ \\
\hline detectable tricuspid regurgitation (n) & 11 & 4 & NA \\
\hline RV systolic pressure (less RA pressure) & $49.6(16.6)$ & $34.5(4.7)$ & $0.02^{1}$ \\
\hline \multicolumn{4}{|l|}{ Radiographic } \\
\hline cardiac silhouette diameter $(\mathrm{cm})^{2}$ & $16.7(2.1)$ & $14.8(1.3)$ & 0.016 \\
\hline central pulmonary artery size (score) & $2.3(0.6)$ & $1.9(0.9)$ & 0.024 \\
\hline peripheral pulmonary artery size (score) & $1.5(0.5)$ & $1.1(0.2)$ & 0.015 \\
\hline cardiac silhouette diameter $(\mathrm{cm})^{3}$ & $16.6(2.3)$ & $15.0(1.3)$ & 0.013 \\
\hline \multicolumn{4}{|c|}{$\begin{array}{l}\text { Abbreviations: NYHA }=\text { New York Heart Association, } \mathrm{NA}=\text { not applicable, } \mathrm{NS}= \\
\text { not significant, } \mathrm{RA}=\text { right atrium. Notes: } 1=\text { only } 4 \text { patients had detectable tricuspid } \\
\text { regurgitation post-closure; } 2=\mathrm{CXR} \text { taken after mean } 4.5(2.1) \text { months; } 3=\mathrm{CXR} \text { taken } \\
\text { after mean } 23.9(11.8) \text { months }(\mathrm{n}=8) .\end{array}$} \\
\hline
\end{tabular}

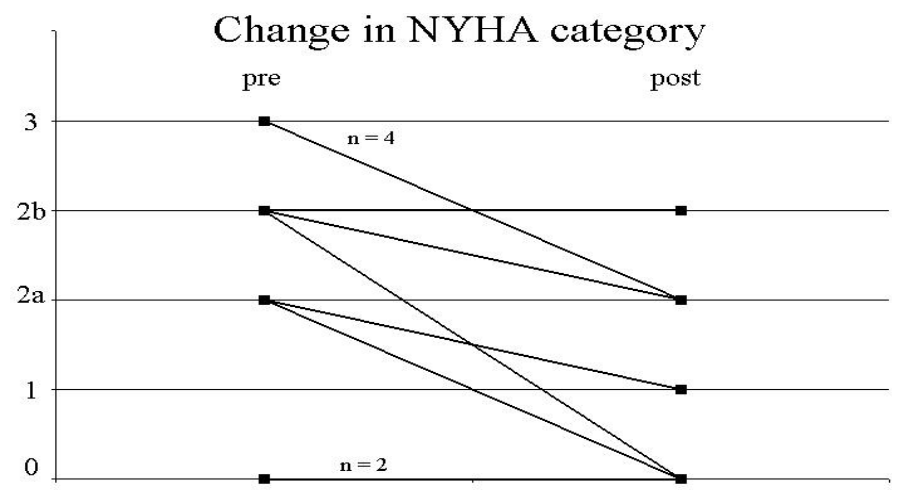

Figure 1. Change in NYHA category

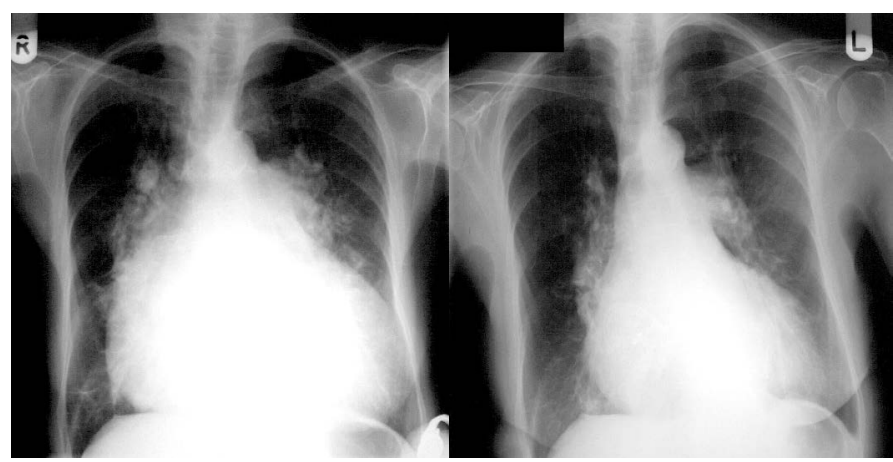

Figure 2. Example of change in CXR appearance

(mean age 67) and showed a reduction in symptoms, RV dimensions and pulmonary artery pressure measured by echo at 12 months (statistics were not applied - see the "limitations" section below for a possible reason why).

We have shown similar benefits from ASD closure in terms of $\mathrm{RV}$ remodelling in elderly patients, albeit in a smaller number, and in addition have shown a semi-quantitative reduction in pulmonary artery size. These beneficial changes are reflected in a significant reduction in cardiac silhouette diameter. We have extended the follow up period out to approximately 2 years and have shown that this reduction in silhouette diameter is maintained.

\section{Limitations}

First, as this was a retrospective study, assessment of breathlessness and other symptoms was not standardised and reviewing doctors were aware of each patient's history i.e. were not blinded. Due to recall bias and lack of blinding of observers, retrospective studies such as ours (no matter what their size) that assess symptoms are not likely to ever demonstrate conclusively the superiority of one approach over the other. There are no prospective trials comparing the effects of ASD closure versus medical therapy on symptoms in the elderly. Nevertheless, the beneficial structural and haemodynamic changes we and others have shown, when considered together with the known and significant symptomatic benefits of ASD closure in younger age groups and the suggestion of a true symptomatic benefit in our small cohort and that of Yalonetsky and Lorber, make it likely that there is a significant reduction in symptoms in the elderly following ASD closure.

Second, RV peak pressure (equating to pulmonary artery peak pressure as no subjects had pulmonary stenosis) was calculated indirectly from the peak velocity of the TR jet. Modern echo machines can detect even very small amounts of TR, sufficient to measure TR velocity. It is interesting, and consistent with the other changes we observed, that some TR was universal pre-procedure but that only 4 patients had TR afterwards. We speculate that this is due to a reduction in "functional" TR secondary to RV dilatation and stretching of the tricuspid valve annulus, as remodelling took place. Unfortunately, the clinical significance (as opposed to the statistical significance) of a fall in peak pressure in only 4 patients is questionable.

Thirdly, LV dimensions were not measured and recorded. Recent additions to the literature have shown that, in younger adults, ASD closure leads to increased left ventricle diastolic diameter and overall function by 6 months [12].

\section{Conclusion}

In summary, haemodynamically significant ASD continue to be diagnosed in patients of all ages, including the elderly, often after long periods with significant attributable symptoms. ASD should be considered in the differential diagnosis of patients with "heart failure" and a clinically or radiographically enlarged heart, in whom there is no other clear cause, and should be detectable by TTE. We suggest that, broadly speaking, percutaneous closure of an ASD should be considered in all adults with symptoms or CXR or TTE signs compatible with right heart volume overload, including the elderly, where the appearance of the ASD suggests percutaneous closure is technically feasible. Our data and those of Swan et al and Yalonetsky and Lorber show that, in the elderly as well as in younger adults and children, it is of structural and haemodynamic benefit.

Finally, in this era in which many septuagenarians and octogenarians undergo cardiac surgery successfully, in patients over the age of 60 in whom percutaneous closure is not technically feasible - usually because the rim of the ASD is incomplete - surgical closure should at least be considered.

\section{Acknowledgement}

We would like to acknowledge with gratitude the help of Dr Anthony Salmon, Consultant Cardiologist, Southampton General Hospital, who performed the majority of these procedures and provided some of the data, and Dr Steve Shaw, Department of Mathematics and Statistics, University of Plymouth, who provided statistical advice and help. 


\section{Conflicts of interest}

There are no conflicts of interest to declare.

\section{References}

1. Murphy JG, Gersh BJ, McGoon MD, Mair DD, Porter CJ, et al. (1990) Long-term outcome after surgical repair of isolated atrial septal defect. Follow-up at 27 to 32 years. N Engl J Med 323:1645-1650. [Crossref]

2. Konstantinides S, Geibel A, Olschewski M, Görnandt L, Roskamm H, et al. (1995) A comparison of surgical and medical therapy for atrial septal defect in adults. $N$ Engl $J$ Med 333: 469-473. [Crossref]

3. Attie F, Rosas M, Granados N, Zabal C, Buendía A, et al. (2001) Surgical treatment for secundum atrial septal defects in patients $>40$ years old. A randomized clinical trial. $J$ Am Coll Cardiol 38: 2035-2042. [Crossref]

4. John Sutton MG, Tajik AJ, McGoon DC (1981) Atrial septal defect in patients ages 60 years or older: operative results and long-term postoperative follow-up. Circulation 64 : 402-409. [Crossref]

5. Ward C (1994) Secundum atrial septal defect: routine surgical treatment is not of proven benefit. Br Heart J 71: 219-223. [Crossref]

6. Webb G (2001) Do patients over 40 years of age benefit from closure of an atrial septal defect? Heart 85: 249-250. [Crossref]
7. Schiller NB, Shah PM, Crawford M, DeMaria A, Devereux R, et al. (1989) Recommendations for quantitation of the left ventricle by two-dimensional echocardiography. American Society of Echocardiography Committee on Standards, Subcommittee on Quantitation of Two-Dimensional Echocardiograms. J Am Soc Echocardiogr 2: 358-367. [Crossref]

8. Schubert S, Peters B, Abdul-Khaliq H, Nagdyman N, Lange PE, et al. (2005) Left ventricular conditioning in the elderly patient to prevent congestive heart failure after transcatheter closure of atrial septal defect. Catheter Cardiovasc Interv 64: 333-337. [Crossref]

9. Ghosh S, Chatterjee S, Black E, Firmin RK (2002) Surgical closure of atrial septal defects in adults: effect of age at operation on outcome. Heart 88: 485-487. [Crossref]

10. Swan L, Varma C, Yip J, Warr M, Webb G, et al. (2006) Transcatheter device closure or atrial septal defects in the elderly: technical considerations and short-term outcomes. Int J Cardiol 107: 207-210. [Crossref]

11. Yalonetsky S, Lorber A (2007) Percutaneous closure of a secundum atrial septal defect in elderly patients. J Invasive Cardiol 19: 510-512. [Crossref]

12. Giardini A, Donti A, Formigari R, Specchia S, Prandstraller D, et al. (2004) Determinants of cardiopulmonary functional improvement after transcatheter atrial septal defect closure in asymptomatic adults. J Am Coll Cardiol 43: 1886-1891. [Crossref]

Copyright: $₫ 2017$ Broadley A. This is an open-access article distributed under the terms of the Creative Commons Attribution License, which permits unrestricted use, distribution, and reproduction in any medium, provided the original author and source are credited. 